\title{
MAPEAMENTO POR MEIO DE GEOPROCESSAMENTO DA VULNERABILIDADE FÍSICO AMBIENTAL AO DESLIZAMENTO DE TERRAS NA REGIÃO METROPOLITANA DE MACEIÓ
}

\author{
Melchior Carlos do Nascimento ${ }^{(a)}$, Sinval Austran Mendes Guimarães Júnior ${ }^{(\mathrm{c})}$, Esdras de Lima \\ Andrade $^{(b)}$, Lionaldo dos Santos ${ }^{(d)}$ \\ (a)Professor Adjunto do Instituto de Geografia, Desenvolvimento e Meio Ambiente (Igdema), Curso de Geografia \\ Bacharelado, Universidade Federal de Alagoas (Ufal). melchior.nascimento@,igdema.ufal.br \\ (b)Professor Assistente do Instituto de Geografia, Desenvolvimento e Meio Ambiente (Igdema), Curso de Geografia \\ Bacharelado, Universidade Federal de Alagoas (Ufal). sinval.autran@igdema.ufal.br \\ ${ }^{(c)}$ Geógrafo do Instituto de Geografia, Desenvolvimento e Meio Ambiente (Igdema), Curso de Geografia \\ Bacharelado, Universidade Federal de Alagoas (Ufal). esdras.andrade @y yahoo.com.br \\ (d) Mestrando do Programa de Pós-Graduação em Geografia, Instituto de Geografia, Desenvolvimento e Meio \\ Ambiente (Igdema), Universidade Federal de Alagoas (Ufal). lionaldo.s@hotmail.com
}

\section{Eixo: GEOTECNOLOGIAS E MODELAGEM ESPACIAL EM GEOGRAFIA FÍSICA}

\begin{abstract}
Resumo
O presente estudo teve como finalidade principal avaliar a vulnerabilidade físico-ambiental aos deslizamentos de terra decorrentes das chuvas intensas na RMM. A partir das análises, foi observado que as ocorrências dos tipos de eventos ou desastres na RMM dependem da interveniência das chuvas e da conjugação de fatores naturais e antropogênicos. Por sua vez, a combinação entre os fatores fisiográficos permitiu identificar que em torno de $44,12 \%$ da área de estudo possuem entre média, alta e muito alta vulnerabilidade físico-ambiental ao deslizamento de terra.
\end{abstract}

Palavras chave: Geoprocessamento, Deslizamento de terra, vulnerabilidade físico-ambiental.

\section{Introdução}

A alteração dos padrões climáticos passa a constituir uma realidade irrefutável, capaz de agravar os problemas políticos e sociais em diferentes partes do mundo. De acordo com Coité e Santos (2012), essa situação deverá repercutir ainda mais nos setores da economia vulneráveis ao clima, tais como a agricultura e pescas, recursos hídricos, florestas e biodiversidade.

Nas áreas urbanas, os transtornos com o desconforto térmico, os problemas de deslizamentos de terra, os alagamentos e as inundações decorrentes das chuvas intensas são as ocorrências mais frequentes. De acordo com Campbell-Lendrum e Corvalán (2007), as grandes cidades deverão se tornar mais vulneráveis ao aquecimento e às inundações por serem geradoras de calor e pela impermeabilização do solo com construções que diminui a capacidade de percolação de águas das chuvas. 
XVII Simpósio Brasileiro

de Geografia Fisica Aplicada

I Congresso Nacional

de Geografia Física

\section{OS DESAFIOS DA GEOGRAFIA FÍSICA NA FRONTEIRA DO CONHECIMENTO \\ Instituto de Geociências - Unicamp \\ Campinas - SP \\ 28 de Junho à 02 de Julho de 2017}

Assim sendo, ao tempo em que o Brasil (2008) destaca que as consequências da variabilidade e o aumento de eventos climáticos são de difícil previsão para a saúde pública, também se admite que as mudanças climáticas podem produzir impactos sobre a saúde humana por diferentes vias.

Em âmbito regional, embora a maior parte do nordeste brasileiro ainda seja consideravelmente afetada pelos prolongados períodos de estiagem, com aproximadamente $60 \%$ da sua extensão suscetível aos efeitos da seca, os episódios associados aos extremos climáticos relacionados às chuvas intensas também têm causado consequências danosas às áreas urbanas, especialmente as mais adensadas. Apesar de as chuvas terem provocado prejuízos consideráveis, a falta de infraestrutura adequada ainda continua sendo a principal responsável, pois a maior parte das cidades brasileiras não contou com um processo planejado de urbanização, tendo suas encostas ocupadas inadequadamente.

No caso da Região Metropolitana de Maceió - RMM, as intervenções que promoveram alterações em sua paisagem natural tiveram início durante o século XVI, nas primeiras incursões mercantilistas ao Brasil. De acordo com Andrade (2010, p.21), o processo de povoamento da região foi determinado pela cultura da cana-de-açúcar, que ocupou preferencialmente as várzeas dos rios que desembocam no Oceano Atlântico. Assim sendo, a faixa costeira do estado de Alagoas, por ter sido a primeira a ser ocupada, teve suas florestas substituídas pelos canaviais e habitações.

Diante desse contexto, pode-se dizer que o crescimento das cidades que integram a RMM e, consequentemente, o seu processo de povoamento foram marcados por distorções espaciais que influenciaram de maneira decisiva a evolução urbana e o seu desenvolvimento social. De acordo com Costa (2001), a partir da última década do século XIX, tendo em vista a importância cultural, econômica e política da cidade de Maceió, esta experimentou um surto de crescimento, quando a população passou a dispor de novo ambiente fisiográfico para desenvolver-se. Para este autor, a cidade cresceu desordenadamente, sem ritmo, sem método, sem estilo.

Independentemente das razões que possam explicar a ocorrência de todos os eventos deflagrados pelas chuvas na RMM, é certo que os problemas a eles relacionados têm causado prejuízos diversos às populações das cidades atingidas, além de evidenciarem a incapacidade do poder público de atuar com a eficácia necessária para sua solução. Assim, é possível considerar o estudo sobre vulnerabilidade físico ambiental como um aspecto relevante na identificação dos problemas urbanos e definição de diretrizes que possam estabelecer as bases adequadas para organização do espaço geográfico, especificamente com vista à redução das situações de riscos.

Desta maneira, as análises realizadas no presente estudo que envolveram, entre outros aspectos, os condicionantes físicos da paisagem e as características predominantes de uso do solo e cobertura vegetal, 
atenderam aos objetivos previamente delineados, e, dessa forma, evidenciaram os níveis de vulnerabilidade físico ambiental da RMM a partir dos deslizamentos de terra.

\section{Materiais e Métodos}

\subsection{Localização e caracterização da área de estudo}

A RMM é formada pelas cidades de Barra de Santo Antônio, Barra de São Miguel, Coqueiro Seco, Maceió, Marechal Deodoro, Messias, Murici, Paripueira, Pilar, Rio Largo, Santa Luzia do Norte e Satuba, possui uma área total de aproximadamente $2.346,162 \mathrm{~km}^{2}$, sendo as sedes urbanas dos referidos municípios ocupam apenas $6,69 \%\left(156,961 \mathrm{~km}^{2}\right)$ da extensão territorial da área de estudo. Localizado entre as latitudes $09^{\circ} 08^{\prime} 17^{\prime \prime}$ e $09^{\circ} 52^{\prime} 12^{\prime \prime}$ 'sul do equador e as longitudes de $35^{\circ} 27^{\prime} 12^{\prime \prime}$ e $36^{\circ} 10^{\prime} 54^{\prime \prime}$ oeste de Greenwich. A Figuras 1 mostra a localização da RMM no território brasileiro, com destaque para sua posição no estado de Alagoas.

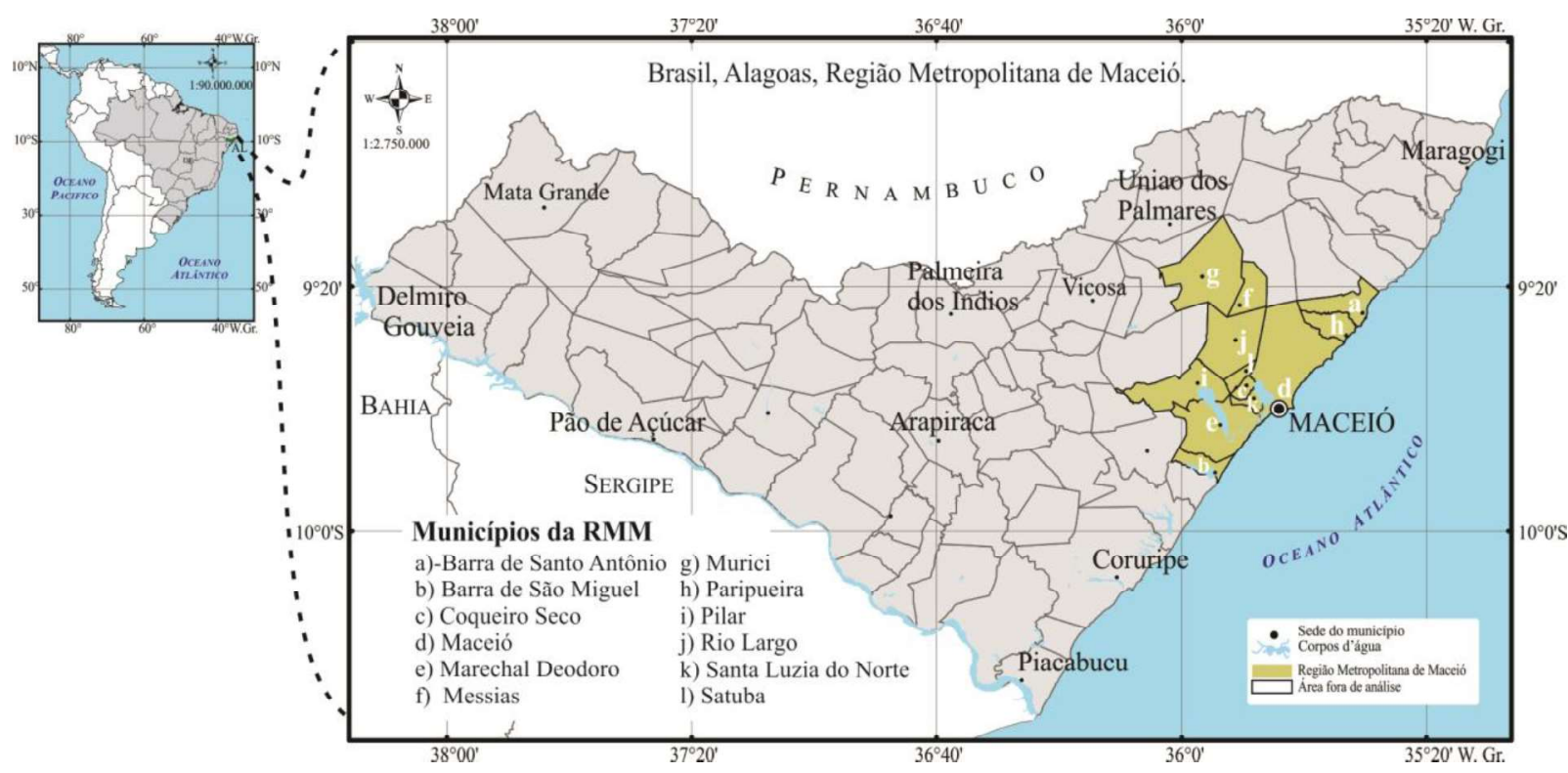

Figura 1 - Localização da Região Metropolitana de Maceió no estado de Alagoas

De acordo com a classificação de Thornthwaite, a RMM apresenta clima subúmido e úmido, com o período quente que se inicia geralmente em setembro e se estende até março, com temperaturas anuais em torno de $22^{\circ} \mathrm{C}$ a $28^{\circ} \mathrm{C}$. O Clima úmido ocorre nos municípios de Barra de Santo Antônio, Coqueiro Seco, Maceió, Paripueira, Pilar, Maceió, Marechal Deodoro, Rio Largo, Santa Luzia do Norte e Satuba. Nesses municípios, a quantidade de chuvas precipitadas em milímetros pela sua média anual é muito superior à Evapotranspiração Potencial ou à quantidade exigida pelas plantas para o seu crescimento e manutenção verde durante todo o ano (ASSIS et al, 2007). O Clima subúmido abrange as demais partes da RMM e 
XVII Simpósio Brasileiro

de Geografia Fisica Aplicada

I Congresso Nacional

de Geografia Física

\section{OS DESAFIOS DA GEOGRAFIA FÍSICA NA FRONTEIRA DO CONHECIMENTO \\ Instituto de Geociências - Unicamp \\ Campinas - SP \\ 28 de Junho à 02 de Julho de 2017}

parcelas dos municípios de Coqueiro Seco, Maceió, Marechal Deodoro, Pilar e Rio Largo. A média anual de chuvas também é superior à da Evapotranspiração Potencial.

A RMM mostra um domínio de terrenos sedimentares, onde se encontram três unidades litológicas: os Sedimentos Quaternários de Praia e Aluvião; os Sedimentos Tércio-quaternários da Formação Barreiras, ambos contidos na Bacia Sedimentar Alagoas e Rochas Cristalinas Intrusivas Ácidas do Complexo MigmatíticoGranítico, do Maciço ou Domínio Pernambuco e Alagoas (DANTAS; CALHEIROS, 1986); e o Domo/Inlier Jirau do Ponciano, contido na Província da Borborema, Subprovíncia Meridional.

As formas de relevo são resultantes da ação da tectônica, litologia e climas atuais e passados, segundo os mapeamentos realizados por Nou et al (1983), do ponto de vista estrutural, são encontrados na RMM as regiões geomorfológicas da Planície Litorânea, dos Piemontes Inumados e do Planalto da Borborema. No caso da Planície Litorânea, são observadas as presenças das unidades geomorfológicas das Planícies Deltaicas, Estuarinas, Praias, Várzeas e Terraços Aluviais. Os Piemontes Inumados são marcados pela presença das unidades geomorfológicas dos Tabuleiros Costeiros, nas quais se registra a presença de Falésias, Encostas/Vales Fluviais, Topos de Interflúvios, Rampas Coluviais, entre outras. O Planalto da Borborema é marcado pela presença da unidade geomorfológica das suas Encostas Orientais, em que é observada a presença marcante de Serras, Vales ou Sulcos Estruturais, Patamares Estruturais, Linhas de Cumeadas e Pontões, entre outros.

A partir dos estudos realizados por Jacomine et al (1975); Wake et al (1983); Brasil (2012), os solos mais representativos da RMM têm sua ocorrência relacionada às unidades geomorfológicas que integram as regiões da Planície Litorânea e dos Piemontes Inumados. As ocorrências nos topos dos Piemontes Inumados são caracterizadas pela presença de Latossolos Amarelos e Latossolos Acinzentados. Já nas encostas, predominam os Argissolos Amarelos, Argissolos Vermelho-Amarelos, Argissolos Acinzentados e os Neossolos Litólicos. Na Planície Litorânea ou Baixada Litorânea, ocorrem os Gleissolos Háplicos (Várzeas e Terraços Fluviais), os Espodossolos Humilúvicos (Terraços Marinhos, Flúvio-marinhos e Flúvio-marinhos lacustres), os Neossolos Flúvicos (Terraços Colúvio-aluvionares e Estruturais), os Neossolos Quartzarênicos (Terraços Marinhos Holocênicos e Pleistocênicos) e os Solos Indiscriminados de Mangues (Alagadiços de Marés/Vasas Flúvio-Marinhas Lagunares).

As áreas de vegetação nativa da área de estudo encontram-se bastante reduzidas, restando algumas parcelas isoladas, principalmente nas encostas dos tabuleiros, nos quais estão presentes remanescentes da Floresta Ombrófila secundária (Mata de Tabuleiro e Mata Serrana) e a Savana (Cerrado). Na Planície Litorânea, são observados resquícios de Formações Pioneiras sob influência Marinha (Restingas Herbáceas) e Flúvio-marinha (ASSIS, 1998; 2000; ALAGOAS, 2010). 
XVII Simpósio Brasileiro

de Geografia Fisica Aplicada

I Congresso Nacional

de Geografia Física

\section{OS DESAFIOS DA GEOGRAFIA FÍSICA NA FRONTEIRA DO CONHECIMENTO \\ Instituto de Geociências - Unicamp \\ Campinas - SP \\ 28 de Junho à 02 de Julho de 2017}

As classes de uso do solo e cobertura vegetal podem ser agrupadas em dois sistemas: um antrópico e outro fitofisionômico. No caso do sistema antrópico, a sua ocorrência é resultado da interferência humana, no qual predominam as áreas agrícolas, urbanas, pastagens, entre outras classes.

\subsection{Materiais utilizados}

Para realização deste estudo foram utilizados as cartas topográficas nas escalas de 1:25.000 (69,19\% de cobertura da RMM), 1:50.000 (26,19\% de cobertura da RMM) e 1:100.000 (4,62\% de cobertura da RMM), as imagens do satélites RapidEye nos intervalos espectrais do azul (440-510nm), verde (520-590nm), vermelho (630-685nm), infravermelho sensível (690-730nm) e infravermelho próximo (760-850nm), obtidas em janeiro de 2011 e disponibilizadas ao Instituto do Meio Ambiente do Estado de Alagoas (IMA) por meio do MMA/PRA.

A base de dados temáticos correspondeu às cartas geológicas da Bacia Sedimentar Sergipe-Alagoas (1973), na escala 1:50.000, elaboradas pelo Convênio Petrobrás/DNPM. O mapa digital de solos, na escala 1:100.000, elaborado pelo convênio da SEAGRI-AL/EMBRAPA SOLOS. De posse dos planos de informações básicos e temáticos digitalizados, georreferenciados e vetorizados, foi possível elaborar os mapas das unidades geomorfológicas e solos, para se adotar como arcabouço o mapa litológico juntamente aos mapas de solos, à declividade e às curvas em nível.

Os componentes cartográficos básicos e temáticos foram obtidos a partir da utilização dos softwares ArcGis, versão 10.1, e ENVI, versão 4.7, respectivamente, usados para vetorização, importação e elaboração dos mapas temáticos e para processamento digital de imagens.

\subsection{Procedimentos metológicos}

A modelagem espacial com vista ao mapeamento das áreas de vulnerabilidade a deslizamento de terra tem sido um aliado no planejamento, prevenção e contingenciamento dos problemas causados pelas chuvas. Nesse sentido, o estudo buscou selecionar e avaliar a eficiência de variáveis físico-ambientais e socioeconômicas, a fim de determinar a vulnerabilidade ao deslizamento de terra às chuvas intensas nos municípios que integram a RMM. Para tanto, abordaram-se os aspectos relacionados às diferentes formas de ocupação do ambiente urbano na perspectiva de uma compreensão sistêmica da realidade. Tal abordagem permitiu entender como as interações entre os atributos físico-ambientais e antropogênicos podem influenciar os níveis de vulnerabilidade dos espaços urbanos aos eventos climáticos relacionados às chuvas intensas.

\subsubsection{Seleção dos indicadores de vulnerabilidade socioambiental}

DOI - 10.20396/sbgfa.v1i2017.2200 - ISBN 978-85-85369-16-3 
XVII Simpósio Brasileiro

de Geografia Fisica Aplicada

I Congresso Nacional

de Geografia Física

\section{OS DESAFIOS DA GEOGRAFIA FÍSICA NA FRONTEIRA DO CONHECIMENTO \\ Instituto de Geociências - Unicamp \\ Campinas - SP \\ 28 de Junho à 02 de Julho de 2017}

Os indicadores foram selecionados com base nas características da área de estudo, considerando-se como aspectos determinantes a facilidade de interpretação, a objetividade, a possibilidade de atualização e a capacidade para definição dos níveis de vulnerabilidade. Tendo em vista a necessidade de modelagem dos dados, utilizou-se o ambiente computacional dos Sistemas de Informações Geográficas (SIG).

Essa etapa do estudo consistiu na definição dos cartogramas temáticos que permitissem correlacionar as características e condições físico-ambientais da área de estudo às diferentes formas de organização espacial. Ao se considerar a gênese, constituição física, forma e estágio de evolução como aspectos determinantes para qualificação do nível de suscetibilidade, foram definidos como variáveis do sistema físico ambiental a litologia, geomorfologia, solos e declividade como cartogramas temáticos.

No caso do sistema antrópico, consideraram-se: a capacidade para identificar as alterações impostas pela ocupação humana e as formas dominantes de uso e ocupação do solo, sendo definido como variável o cartograma de uso do solo e cobertura vegetal, mapeado a partir das imagens de satélite.

Considerando os níveis variados de suscetibilidade que cada um deles pode representar, foram atribuídos os valores 1, 2, 3, 4 e 5, respectivamente, muito-baixo, baixo, médio, alto e muito-alto, para determinar diferenças entre as classes correspondentes a cada cartograma, sendo adotado o valor 0 (zero) quando essa não estiver sujeita à ocorrência do evento ou fora da análise. Tal definição foi baseada nas propriedades e características das classes mapeadas e na capacidade de interveniência das dinâmicas climáticas sobre cada uma delas.

\subsubsection{Definição de notas para os planos temáticos}

A decisão pela utilização do cartograma de unidades litológicas foi motivada por essa variável físico-ambiental ser capaz de contribuir para revelar a localização das parcelas do território mais propícias às ocorrências de deslizamentos de terra, de forma a reduzir as dúvidas ou incertezas quando da realização das operações de álgebras de mapas. Além disso, a ação pluviométrica sobre alguns componentes geológicos pode promover efeitos físicos e químicos capazes de influenciar de maneira variada o grau de intemperismo. Portanto, buscando qualificar os diferentes níveis de vulnerabilidade a deslizamento de terra, foram atribuídas as notas para cada classe litológica mapeada, conforme descrito na Figura 2.

As características morfométricas do terreno, a intensidade de dissecação do relevo e a amplitude altimétrica consistem em elementos da paisagem associados à geomorfologia, capazes de revelar o grau de suscetibilidade às dinâmicas hidrológicas e pluviométricas. Por essas razões, optou-se em incluir na matriz de análise do presente estudo o plano de informação espacial correspondente às unidades geomorfológicas. Para facilitar as 


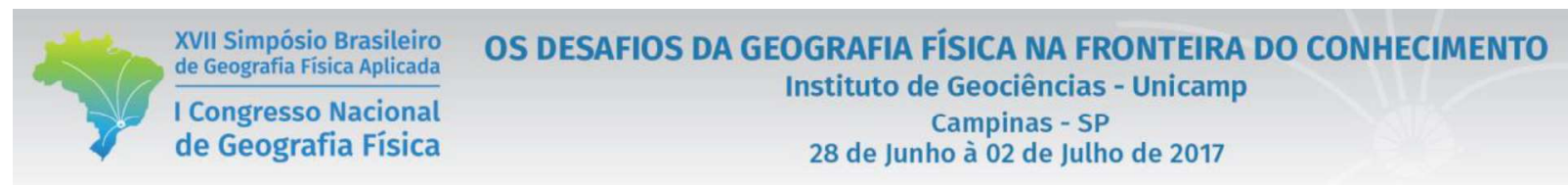

combinações dos planos de informações temáticos, as unidades geomorfológicas mapeadas foram agrupadas e qualificadas quanto a sua suscetibilidade aos processos de deslizamentos terra (Figura 3).

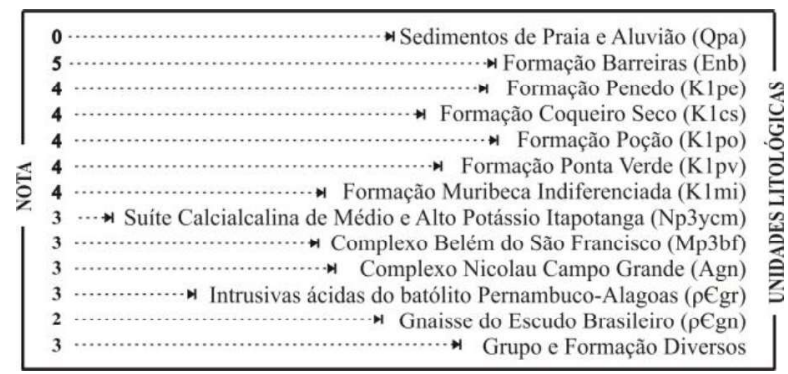

Figura 2 - Escala de vulnerabilidade a deslizamento de terra das unidades litológicas predominantes na RMM.

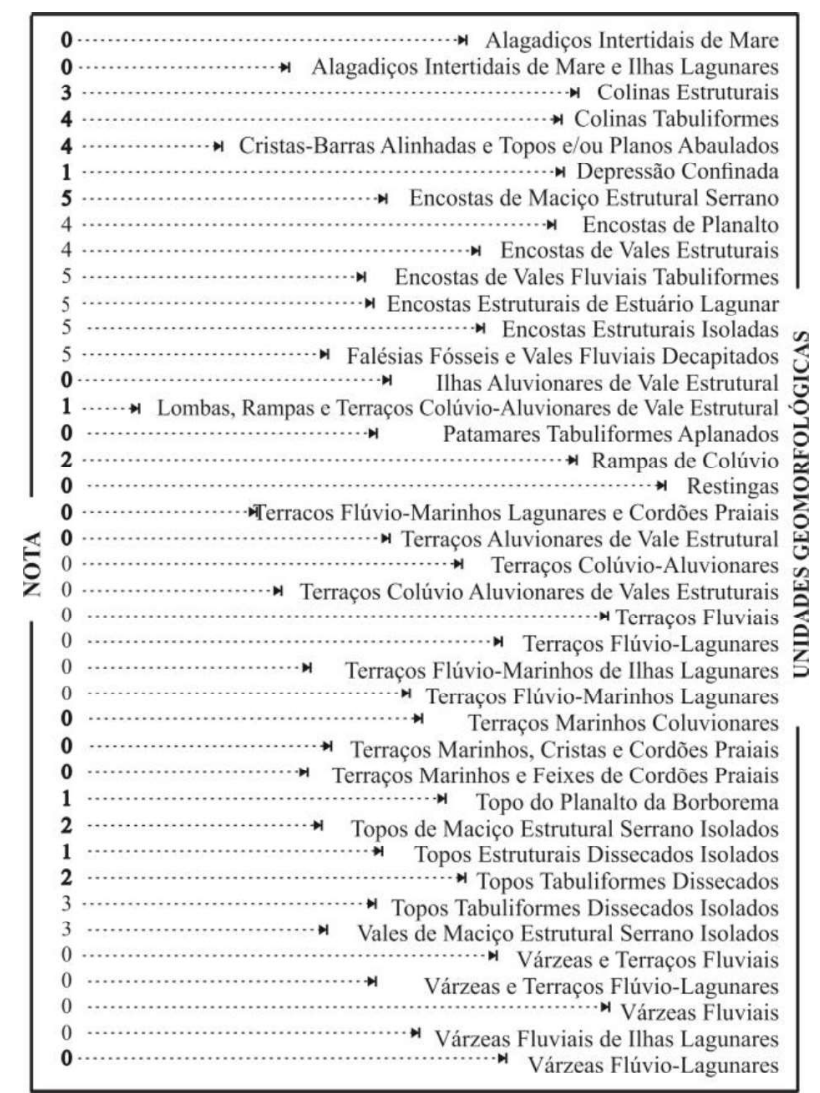

Figura 3 - Escala de vulnerabilidade a deslizamento de terra das unidades geomorfológicas predominantes na RMM.

Por representar uma componente suscetível às precipitações pluviométricas e dinâmicas hidrológicas, as unidades de solos foram selecionadas como relevante variável físico-ambiental útil à análise da vulnerabilidade aos deslizamentos de terra. Crepane et al (2001, p. 82) destacam que a causa fundamental da erosão hídrica, seja laminar, em sulcos ou ravinas, é a ação da chuva sobre o solo. Para esses autores, a menor ou maior suscetibilidade de um solo sofrer os processos erosivos da morfogênese depende da 


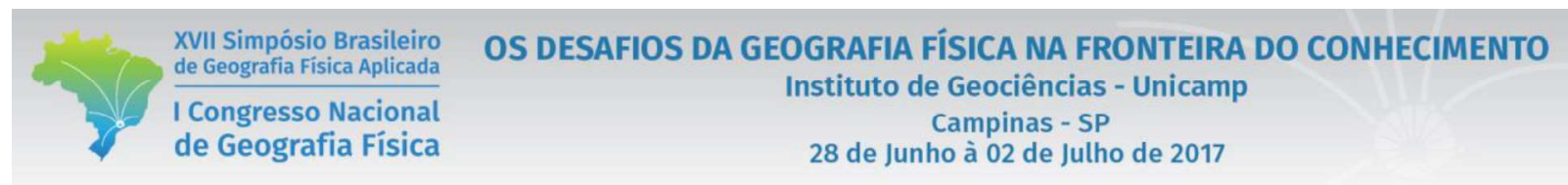

sua estrutura, tipo e quantidade das argilas, permeabilidade e profundidade do solo e a presença das camadas impermeáveis. Com bases nessas considerações e na forma de distribuição e ocorrência dos solos na área de estudo, atribuíram-se as notas descritas na Figura 4.

As faixas de declividade desempenham uma função decisiva na avaliação da vulnerabilidade da paisagem aos deslizamentos de terra. De acordo com Crepane et al (2001, p. 75), quanto maior a declividade, mais rapidamente a energia potencial das águas pluviais transforma-se em energia cinética e maior é, também, a velocidade das massas de água e sua capacidade de transporte. Ao contrário disso, os terrenos de menor declividade consistem em ambientes de acumulação, isto é, áreas sujeitas às dinâmicas hidrológicas. Dessa maneira, as faixas de declividade descritas na Figura 5 basearam-se no estudo desenvolvido por Crepane et al (2001) admitiram tais intervalos de declividade apropriados para as escalas igual ou maior que 1:100.000.

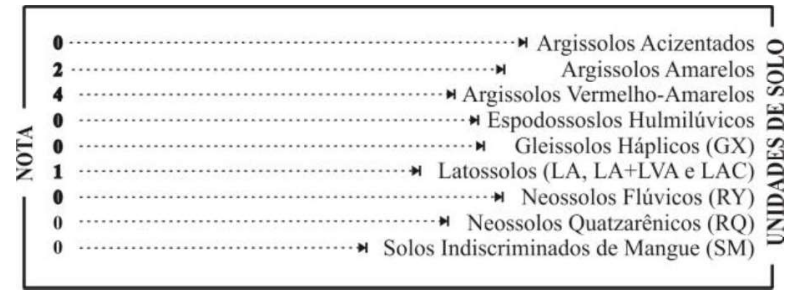

Figura 4 - Escala de vulnerabilidade a deslizamento de terra das unidades de solos predominantes na RMM

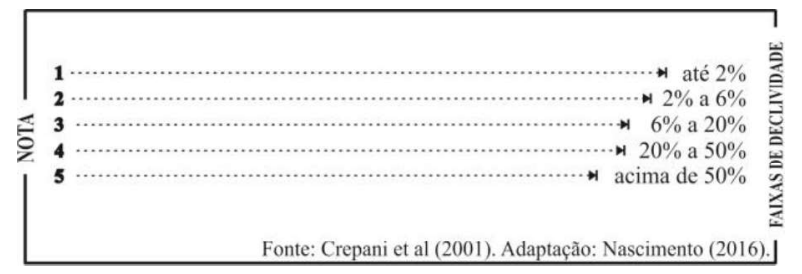

Figura 5- Escala de vulnerabilidade a deslizamento de terra as faixas de declividade predominantes na RMM

A atribuição de valores qualificando as classes pertencentes ao mapa de uso do solo e cobertura vegetal considerou como critério a alteração na composição e diversidade da vegetação, em geral capaz de influenciar na compactação dos solos e nos processos erosivos, consequentemente, nas dinâmicas pluviométricas e hidrológicas. Portanto, as áreas edificadas (áreas e sítios urbanos) e as áreas agrícolas possuem tal característica, isto é, ambas resultam da presença e intervenção direta do ser humano na paisagem, por conseguinte, receberam as maiores notas (Figura 6).

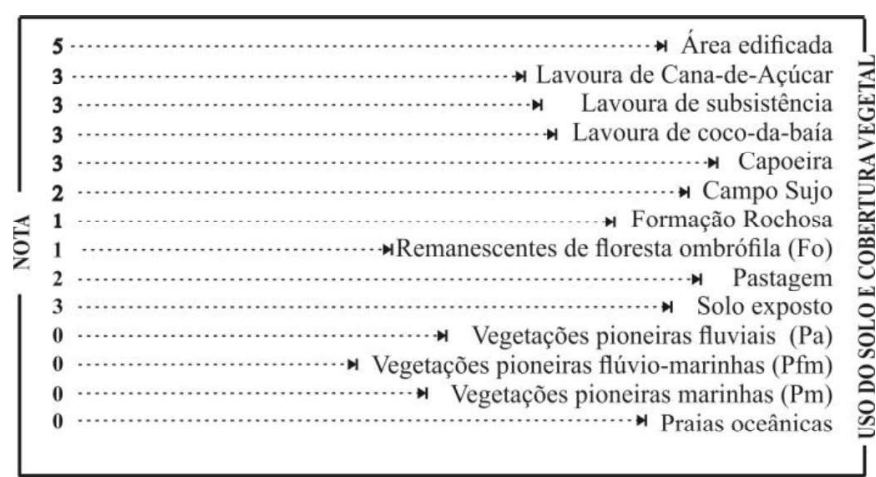

Figura 6 - Escala de vulnerabilidade a deslizamento de terra das classes de uso do solo e cobertura vegetal predominantes na RMM 
XVII Simpósio Brasileiro de Geografia Fisica Aplicada

I Congresso Nacional de Geografia Física

\section{OS DESAFIOS DA GEOGRAFIA FÍSICA NA FRONTEIRA DO CONHECIMENTO \\ Instituto de Geociências - Unicamp \\ Campinas - SP \\ 28 de Junho à 02 de Julho de 2017}

\section{Resultados e Discussões}

\subsection{As áreas predominantes de uso do solo e cobertura vegetal da RMM}

As imagens do satélite RapidEye e os levantamentos de campo permitiram identificar e mapear 17 (dezessete) classes de uso do solo e cobertura vegetal predominantes na RMM. Observando a Tabela I a seguir, é possível verificar que a cana-de-açúcar e pastagem foram as classes de maiores ocorrências na área de estudo, com 918,89km2 e 444,96km2, respectivamente. Juntas, essas classes ocupam aproximadamente 57,91\% da RMM, reforçando a influência econômica e os intensos processos antrópicos aos quais têm sido submetidas.

Tabela I - Classes de uso do solo e cobertura vegetal identificadas na RMM

\begin{tabular}{c|l|c|c}
\hline \multirow{2}{*}{ ITEM } & \multicolumn{2}{|c|}{ USO DO SOLO E COBERTURA VEGETAL } & \multicolumn{2}{|c}{ ÁREA } \\
\cline { 3 - 4 } & & $\mathbf{K m}^{\mathbf{2}}$ & $\mathbf{\%}$ \\
\hline 1 & Área edificada & 160,83 & 6,83 \\
2 & Campo Sujo & 96,43 & 4,09 \\
3 & Cana-de-açúcar & 918,89 & 39,02 \\
4 & Capoeira & 18,53 & 0,79 \\
5 & Coco-da-baía & 29,76 & 1,26 \\
6 & Corpos d'água & 104,10 & 1,26 \\
7 & Formação arenosa & 2,90 & 0,12 \\
8 & Vegetação Pioneira Fluvial & 77,42 & 3,29 \\
9 & Vegetação Pioneira Flúvio-marinha & 26,07 & 1,11 \\
10 & Formação Rochosa & 1,24 & 0,05 \\
11 & Lavoura de subsistência & 6,42 & 0,27 \\
12 & Pastagem & 444,96 & 18,89 \\
13 & Poços de Petróleo & 0,65 & 0,03 \\
14 & Praia & 2,88 & 0,12 \\
15 & Reflorestamento & 0,11 & 0,00 \\
16 & Remanescente florestal & 407,77 & 17,31 \\
17 & Solo exposto & 56,25 & 2,39 \\
\hline
\end{tabular}

\subsection{Vulnerabilidade físico-ambiental a deslizamentos de terra}

Os deslizamentos de terra se constituem em um processo erosivo que induz diretamente o desprendimento do solo das altas e médias encostas desprovidas de cobertura vegetal ou ocupadas de forma indevida (Figura 7). A participação percentual das classes que integram os planos temáticos de informações (PTI) usados no presente estudo por faixas de vulnerabilidade físico-ambiental ocorrem de forma variada. As classes que integram os planos temáticos de informações considerados como muito baixa (nota 1) vulnerabilidade correspondeu a um percentual de 26,18\%. Dentre os planos temáticos de informações utilizados, a declividade concentrou a classe com maior extensão de ocorrência na RMM; em torno de $1.183,32 \mathrm{~km}^{2}$, foram consideradas áreas com muito baixa vulnerabilidade a deslizamento de terra. Esses resultados corroboram os estudos realizados por Nou et al (1983), que identificaram os ambientes com tendência à instabilidade de dinâmica fraca como o mais abrangente na RMM. 


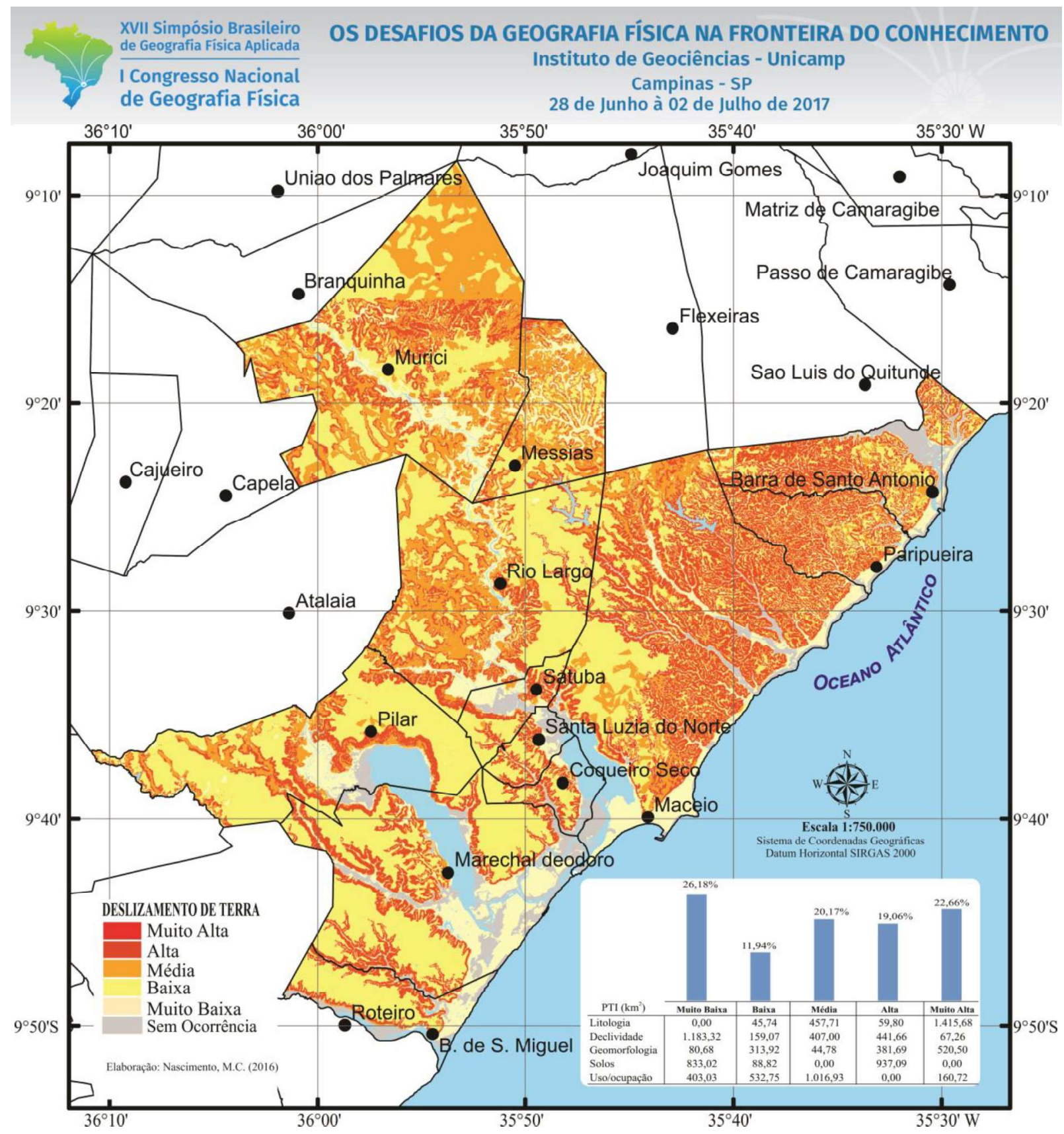

Figura 7 - Distribuição da área ocupada pelas classes que integram os PTI por faixa de vulnerabilidade a deslizamento de terra.

Já as classes inseridas nas faixas muito alta (nota 5) representam a segunda maior participação em termos percentuais, ou seja, em torno de $22,66 \%$ da extensão da área de estudo. Nesse caso, as classes pertencentes aos planos de informações litológicas $\left(1.415,68 \mathrm{~km}^{2}\right)$ e geomorfológicas $\left(520,50 \mathrm{~km}^{2}\right)$ ocupam as maiores extensões na faixa de vulnerabilidade considerada muito alta.

A integração dos referidos planos de informações temáticas permitiu identificar as áreas vulneráveis aos deslizamentos de terra na RMM (Mapa 3). A Tabela II a seguir mostra, por um lado, que a maior parte da área de 
XVII Simpósio Brasileiro

de Geografia Fisica Aplicada

I Congresso Nacional

de Geografia Física

\section{OS DESAFIOS DA GEOGRAFIA FÍSICA NA FRONTEIRA DO CONHECIMENTO \\ Instituto de Geociências - Unicamp \\ Campinas - SP \\ 28 de Junho à 02 de Julho de 2017}

estudo possui baixa vulnerabilidade físico-ambiental a deslizamento de terra $\left(856,92 \mathrm{~km}^{2}\right)$, aproximadamente $36,38 \%$ de sua extensão territorial. Por outro lado, as áreas consideradas com muito alta vulnerabilidade representam apenas $0,42 \%\left(9,81 \mathrm{~km}^{2}\right)$ da RMM e estão concentradas, em sua maior parte, na cidade de Maceió.

Tabela II - Área total das faixas de vulnerabilidade físico-ambiental ao deslizamento de terra da RMM

\begin{tabular}{lcc}
\hline Vulnerabilidade a deslizamento de terra & $\mathbf{k m}^{\mathbf{2}}$ & $\mathbf{\%}$ \\
\hline Sem Ocorrência & 228,55 & 9,70 \\
Muito Baixa & 230,60 & 9,79 \\
Baixa & 856,92 & 36,38 \\
Média & 438,28 & 18,61 \\
Alta & 591,04 & 25,09 \\
Muito Alta & 9,81 & 0,42 \\
TOTAL & $\mathbf{2 . 3 5 5 , 2 0}$ & $\mathbf{1 0 0 , 0 0}$ \\
\hline
\end{tabular}

Ainda observando a Tabela II acima, é possível verificar que a maior parte da RMM é formada por áreas consideradas entre muito baixa a média vulnerabilidades ao deslizamento de terra, sendo o somatório delas equivalente a $64,78 \%$ da referida área de estudo. De acordo com a integração dos planos temáticos de informações usados no presente estudo, as áreas consideradas com alta vulnerabilidade aos problemas de deslizamento de terra ocupam uma extensão de $591,04 \mathrm{~km}^{2}$, isto é, aproximadamente $1 / 4(25 \%)$ da RMM.

De maneira geral, a maior parte da RMM possui baixa vulnerabilidade a deslizamento de terra, mas, se observados os resultados isoladamente, por município, é possível verificar que em algumas cidades predominam as áreas consideradas de alta vulnerabilidade. Tal fato pode ser constatado quando se verificado que nos municípios metropolitanos da Barra de Santo Antônio (76,99 $\left.\mathrm{km}^{2}\right)$, Maceió $\left(186,96 \mathrm{~km}^{2}\right)$ e Paripueira $\left(65,94 \mathrm{~km}^{2}\right)$ predominam as áreas com alta vulnerabilidade. Embora esses municípios tenham em seus históricos de ocorrências problemas variados relacionados às chuvas intensas, observou-se durante as incursões em campo que os mais frequentes estão associados aos deslizamentos de terra.

\section{Considerações finais}

A partir da análise integrada das variáveis geomorfológicas, pedológicas, litológicas, declividade e das formas predominantes de ocupação humana no espaço geográfico metropolitano de Maceió, foi possível identificar as áreas e estimar os graus de vulnerabilidade físico-ambiental aos eventos relacionados aos deslizamentos de terra. A preservação das espécies que constituem os diferentes ambientes fitogeográficos presentes na RMM tem sido um aliado importante; por isso, torna-se essencial a adoção de critérios que assegurem a proteção desses ambientes. Portanto, como alternativa para atenuar os efeitos das chuvas intensas sobre as encostas, sugere-se uma ação socioambiental de remanejamento das famílias residentes 


\section{OS DESAFIOS DA GEOGRAFIA FÍSICA NA FRONTEIRA DO CONHECIMENTO \\ Instituto de Geociências - Unicamp \\ Campinas - SP \\ 28 de Junho à 02 de Julho de 2017}

para áreas adequadas à ocupação humana, além da recuperação e preservação da vegetação por meio da implantação de programa integrado de fiscalização e educação ambiental.

\section{Referências}

ALAGOAS, Governo do Estado de Alagoas, IMA, Instituto do Meio Ambiente do Estado de Alagoas. Cobertura vegetal do estado de Alagoas \& mangues de Alagoas. (Coord. Afrânio Farias de Menezes). Maceió: Instituto do Meio Ambiente do Estado de Alagoas; Petrobrás, 2010, 202p.

ANDRADE, M. C. Usinas e Destilarias em Alagoas. Maceió: EDUFAL, 2. ed., v. 1, 140 p. 2010.

ASSIS, J. S. Biogeografia e conservação da biodiversidade - projeções para Alagoas. Maceió: Catavento, 2000. 200p.

ASSIS, J. S.; ALVES, A. L.; NASCIMENTO, M. C. Atlas Escolar de Alagoas - Estudo Geo-Histórico e Cultural. João Pessoa: Grafset, 210 p. 2007.

ASSIS, J.S. Um projeto de Unidades de Conservação para o Estado de Alagoas. Rio Claro: IGCE/UNESP, 1998. Tese (Doutorado em Geografia - Organização do Espaço). IGCE/UNESP, 1998. 241p.

BRASIL, Ministério da Agricultura Pecuária e Abastecimento/Empresa Brasileira de Pesquisa Agropecuária Embrapa; ALAGOAS, Secretaria de Estado da Agricultura e Desenvolvimento Agrário - SEAGRI-AL. Levantamento de Reconhecimento de Baixa e Média Intensidade dos Solos do Estado de Alagoas. Recife: Embrapa Solos, 2012, 238p. 1 DVD-ROM (Relatório Técnico).

BRASIL. Ministério da Saúde. Mudanças climáticas e ambientais e seus efeitos na saúde: cenários e incertezas para o Brasil. In: BRASIL. Ministério da Saúde; Organização Pan-Americana da Saúde. Brasília: Organização PanAmericana da Saúde, 40p. 2008.

CAMPBELL-LENDRUM, D.; CORVALAN, C. Climate Change and Developing-Country Cities: Implications for Environmental Health and Equity. Journal of Urban Health, v. 84, n. 1, p. 109- 117, 2007.

COITÉ, M. E SANTOS, S. T. Integração das Mudanças Climáticas nos Processos de Desenvolvimento Nacional e na Programação Nacional das Nações Unidas: Guia para Apoiar as Equipas da ONU nos Países na Integração dos Riscos e Oportunidades Climáticas, 2012.

COSTA, C. Maceió. Maceió: Catavento, 2001, 180 p. 


\section{OS DESAFIOS DA GEOGRAFIA FÍSICA NA FRONTEIRA DO CONHECIMENTO \\ Instituto de Geociências - Unicamp \\ Campinas - SP \\ 28 de Junho à 02 de Julho de 2017}

CREPANI, E.; MEDEIROS, J. S.; HERNANDEZ FILHO, P.; FLORENZANO, T. G.; DUARTE, V.; BARBOSA, C. C. F. Sensoriamento remoto e geoprocessamento aplicados ao zoneamento ecológico-econômico e ao ordenamento territorial. Instituto Nacional de Pesquisas Espaciais - INPE, Santa Maria-RS, 103 p. 2001.

DANTAS, José Robinson Alcoforado; CALHEIROS, Mário Eugênio de Vasconcelos. Estratigrafia e geotectônica. In: BRASIL - DNPM. Mapa geológico do Estado de Alagoas: texto explicativo. Recife: DNPM, 1986. p.7-50.

JACOMINE, P. K. T. et al. Levantamento exploratório-reconhecimento de solos do Estado de Alagoas. Recife: EMBRAPA/SUDENE, 1975. 532 p. (Boletim Técnico, 35).

NOU, E.A.V.; BEZERRA, L.M.M.; DANTAS, M. Geomorfologia. In: Brasil, Ministério das Minas e Energia, Secretaria Geral, Projeto Radambrasil. Folhas SC. 24/25 Aracaju/Recife. Rio de Janeiro: DIPUB/RADAMBRASIL, 1983. p. 347-443 (Série: LRN. V. 30)..

WAKE. M.; VIANA, C.D.B.; SOUZA, C.G. Pedologia: levantamento exploratório de solos. In: BRASIL, MINISTÉRIO DAS MINAS E ENERGIA, SECRETARIA GERAL, Projeto Radambrasil. Folhas SC 24/25 Aracaju/Recife. Rio de Janeiro: DIPUB/RADAM BRASIL, 1983. P. 455-572 